\title{
Alignment Effect between Electronic Business Strategy and Information Technology Capabilities on Value Creation in Employing Industrial Internet of Things
}

\author{
Yue-Yang Chen, ${ }^{1}$ Hui-Ling Huang, ${ }^{2 *}$ and Shih-Fu Sung ${ }^{3}$ \\ ${ }^{1}$ Department of Business Administration, I-Shou University, \\ No. 1, Sec. 1, Syuecheng Rd., Dashu District, Kaohsiung City 84001, Taiwan \\ ${ }^{2}$ Department of Business Administration, Chang Jung Christian University, \\ No. 1, Changda Rd., Gueiren District, Tainan City 71101, Taiwan \\ ${ }^{3}$ Department of Information Management, I-Shou University, \\ No. 1, Sec. 1, Syuecheng Rd., Dashu District, Kaohsiung City 84001, Taiwan
}

(Received March 11, 2020; accepted February 3, 2021)

Keywords: electronic business (e-Business), e-Business strategy, e-Business capabilities, alignment, value creation, industrial Internet of Things (IIoT)

In the highly global competitive environment, companies are switching their sales channel from "bricks-and-mortar" to "clicks-and-mortar" by adopting advanced information technology (IT) and Internet-based systems to act as electronic business (e-Business) companies. In this regard, companies must have the capabilities to integrate their advanced IT resources into operational activities, especially for e-Business companies that try to link and share their information to support customers and suppliers in the supply chain. So far, although several studies have examined the alignment between business strategy and IT strategy, there has been little attempt to explore the alignment (or fit) relationships between e-Business industrial Internet of Things (IIoT) strategy and e-Business capabilities, or their alignment effect on value creation. Consequently, we develop an alignment model to demonstrate their performance implications on e-Business value creation. We hope that this e-Business IIoT alignment model will not only provide more definitive answers about the nature of e-Business with an alignment perspective than previous research, but also provide a guideline for management practices in the IIoT management field. The perspective of "fit as covariation" was used to test the e-Business IIoT alignment model in order to support its internal consistency relationships. The results obtained from empirical data collected from 187 companies showed that the alignment between e-Business IIoT strategy and e-Business IIoT capabilities has a significant impact on the value creation of a firm. The results of this research suggest that e-Business companies should allocate their resources to reinforce technology capabilities to match with various IIoT strategies to maximize their competitive advantages.

\footnotetext{
*Corresponding author: e-mail: ling@mail.cjcu.edu.tw
} https://doi.org/10.18494/SAM.2021.2856 


\section{Introduction}

In the ever-changing business operations environment, firms need to follow and adopt advanced information technology (IT) to compete with their competitors. With the continuous emergence of information software and the maturation of transmission speed and network technology, more people are realizing the importance of Internet applications, which have expanded from the mobile Internet, search engines, and online communities to e-commerce. Internet technology provides more opportunities for firms to establish distinctive strategic positioning than did previous generations of IT. $^{(1)}$

The importance and the role of Internet-based technologies in supporting company operations have received widespread interest from both academics and practitioners. Indeed, using Internet applications, companies can strengthen their marketing and operation capacities. ${ }^{(2)}$ Because of the formation and development of the network economy system, global e-commerce is growing continuously, with enterprises swarming to participate in e-operational environments and e-commerce. ${ }^{(3)}$ Evidence has shown that the potential benefits of electronic business (e-Business) technologies include improved speed and flexibility for delivery, lower prices from suppliers, lower transaction costs, higher customer service levels, and reduced investment in supply chain inventories. ${ }^{(4)}$ In this vein, enterprises interact with the target customers using e-devices or Internet communications techniques and carry out transactions with their customers and suppliers via their websites.

However, not all organizations are well prepared or well composed to successfully launch and maintain an e-Business initiative. This is because e-Business initiatives are often perceived as risky and challenging, especially for bricks-and-mortar companies facing challenges such as a lack of e-Business skills, resistance of employees to redesigning processes, and the ambiguity associated with changing the IT infrastructure of the company. ${ }^{(5)}$ From the viewpoint of process design, Internet applications of e-Business are not stand-alone technologies; they must be integrated into the overall business value chain. ${ }^{(6)}$ That is, firms must find ways to connect operations, marketing, finance, customer relationship management, human resource management, and business strategy seamlessly from internal to external. ${ }^{(7)}$ From the viewpoint of system design, an e-Business system aggregates multiple components such as applications, services, and platforms. Thus, data, processes, and computer networks must be integrated into related systems (e.g., SCM, ERP, KMS, CRM) via unification (of methods, architectures, constructs, or reusable partial models) or via federation (of interfaces, reference model, or ontology). Accordingly, it is necessary to probe the way in which companies deploy their technological resources in order to activate their e-Business processes and to determine whether they are aligned with the right business strategy.

Recently, individuals and firms have been able to connect everything and monitor activities through the Internet, which is implanted in every aspect of our daily lives. Healthcare, manufacturing, retail, transportation, energy-aware buildings, our homes, and so forth are now being controlled and monitored by these connected devices, ${ }^{(8)}$ 
which means that many of the objects that surround us will be linked on the network simultaneously. ${ }^{(9)}$ In order for companies not to fall behind, their traditional operational process is now transforming from traditional stores to a combination of sensors and analytics that allow real-time access to data that were previously unavailable. Hence, entering the industrial Internet of Things (IIoT), more and more enterprises are establishing appropriate IoT plans and strategies, starting to invest in information and communication technology (e.g., sensors, actuators, and intelligent devices), enhancing the related infrastructure, and combining suppliers, customers, and stakeholders as the goals to treat e-Business practices as the "Stars". (10) Thus, it is important for E-business companies to adopt the latest IT (i.e., IoT, sensors, etc.) to enhance their capabilities. Although there are many ways for enterprises to maximize their competitive advantages, the best and most effective way to achieve this depends on the presence of significant IIoT capabilities in the era of Industry 4.0. ${ }^{(11)}$ In addition, despite the recent buoyancy of the e-Business literature and some frameworks to explain and clarify the relationship between IoT and e-Business strategy, the alignment perspective has not been demonstrated or empirically examined in this field. Therefore, the purpose of the present study is to provide insights into the performance implications of alignment between e-Business IIoT strategy and IIoT capabilities on e-Business value creation by employing a fit as a covariation perspective.

\section{Theoretical Background}

\section{1 e-Business IIoT strategy}

Firms should take offensive or defensive actions to create a superior position in an industry and seek to respond to the external environment (various kinds of competitive forces) effectively to gain competitive advantages. ${ }^{(12)}$ Strategies can serve as a competitive weapon to achieve corporations' missions and objectives. ${ }^{(13)}$ Thus, business strategy is "the outcome of decisions made to guide an organization with respect to the environment, structure and processes that influence its organizational performance."(14) It has been defined as the "competitive tools used to give an organization its 'distinctive competence' which depends on task environment characteristics." (15)

Many enterprises have failed to align their e-Business strategy well because they did not follow a business-level strategy, especially in adopting advanced IoT and related sensor technologies. Despite many failures in e-commerce, business-to-business commerce and business-to-consumer commerce are still expanding at an extremely rapid rate. Regarding the classification of e-Business strategy, a popular one is based on the process supported by new IIoT technologies, which are driving the evolution towards a smart manufacturing enterprise that is more efficient, safer, and sustainable. ${ }^{(16)}$ In fact, supply chain management refers to the management of different processes such as customer relationship management, customer service, demand management, order management, production and material flows, and purchasing. ${ }^{(17)}$ The underlying function of IIoT is for smart connected assets (i.e., "things") to 
operate as part of a larger system or a system of systems that make up the smart manufacturing enterprise. These activities are the formation of e-Business IIoT strategy. Specifically, the IoT and related sensor technologies are applied to innovate value propositions, value delivery, and value creation in industries such as energy, finance, facility management, healthcare, homes and workspaces, and manufacturing. ${ }^{(18)}$ In general, Internet tools have been defined as three aspects: e-commerce, ${ }^{(19)}$ which supports sales, distribution, and customer service processes; e-procurement, ${ }^{(20)}$ which supports sourcing, procurement, tendering, and order fulfillment processes; and e-manufacturing, ${ }^{(21)}$ which supports demand and capacity planning, forecasting, and internal supply chain integration. The concept of e-business IIoT strategy has been introduced to address the issue of how IoT technologies can reshape companies and provide competitive advantages. Thus, the three-category dimension then is extended and used in the present study as representatives of e-Business IIoT strategy.

\section{2 e-Business IIoT capabilities}

e-Business capabilities can be defined as "the ability of a firm to use Internet technologies to share information, process transactions, coordinate activities, and facilitate collaboration with suppliers and customers." ${ }^{\prime(6)}$ Strategic use of IT means that firms enhance productivity, profitability, and performance by using IT. ${ }^{(14,22)}$ Dynamic capability reflects a firm's strategic initiatives to share its information, facilitate transactions, improve customer services, and strengthen supplier integration by using the Internet. ${ }^{(23)}$

At present, most companies have implemented IT/IS to improve operational performance and their competitive advantages. IT is regarded as a critical resource for organization. Thus, many industrial and academic experts have proposed the construction of IT capacity. A development and implementation information system has been regarded as an important event, which includes the relationship between IT and interdepartmental cooperation. Through the introduction of a great number of ICTs and seamless integration, enterprises accomplish the goal of e-Business orientation. The ICT integration mechanism is a management tool to coordinate different units internal and external to the organization. ${ }^{(24)}$ According to Ref. 25, Internet technologies have potential for value creation by linking companies, suppliers, and customers in new ways. Therefore, the ICT capabilities of a firm refer to its ability to combine independent and subordinate information systems and Internet technologies to support overall organizational goals. ${ }^{(26)}$ Information system integration allows enterprises with e-Business to consistently deal with orders and guarantees the consistency of different systems in order to reduce the time of the product development cycle and inventory costs. By integration, enterprises can combine information systems with different functions for seamless connection of information and processes in various information systems. e-Business capabilities can be reinforced to strengthen the competitiveness of value chain or supply chain members. ${ }^{(27)}$

Meanwhile, to cultivate e-Business IIoT capabilities, firms must have a holistic picture for their business and to envision the business processes that technology makes possible. ${ }^{(28)}$ The IT department and team members of a firm should be familiar with business processes to improve existing processes or to reshape these processes with the right IT solutions. Companies must 
get the business constructively engaged in technology issues to obtain an understanding of the potential of the IT that firms can use in e-Business initiatives. In addition, firms must have the ability to integrate IIoT efforts with business purposes and activities. Industrial Internetbased technologies make a connected enterprise by merging the information and operational department of the industry. Thus, managers must have the vision to align e-Business objectives with IT (i.e., IIoT) objectives to improve visibility, boosting operational efficiency, increasing productivity, and reducing the complexity of processes in the industry. To incorporate best practices in management with IS/IT governance, best practices must be defined as the acquisition and implementation of processes with superior performance. ${ }^{(28)}$

\subsection{Value creation in e-Business}

Nowadays, more and more traditional companies are investing a lot in deploying e-Business in internal value chain and external supply chain activities to improve quality, lower cost, increase flexibility, improve customer satisfaction, and strengthen overall business operational capabilities. Value creation in e-Business is one of the most pivotal issues in deciding e-Business component investments. Following this reasoning, Martinez and Jarillo indicated that four dimensions represent groups of factors that can enhance different total values created by e-Business, namely, novelty, lock-in, complementarities, and efficiency. ${ }^{(25)}$

Novelty is defined by the level of uniqueness of goods or services offered by a firm regarding how the customers' needs are satisfied and what those needs are. It includes introducing new transaction structures and content, new products and services, new methods of production, distribution, and marketing. Novelty can be achieved by devising new ways of satisfying existing needs or finding and addressing entirely new needs for stakeholders for a firm.

Lock-in concerns the various kinds of costs that customers need to bear if they were to replace the firm's product with one of its competitors; it is assumed that the higher the switching costs, the tighter the customer lock-in. Lock-in is enhanced by two means: customers who are motivated to repeat their transactions, and partners who are willing to maintain a durable association with the focal firm. ${ }^{(29)}$

Complementarities are determined by the extent of completeness of customer need fulfillment by the firm and its business partners. Resource-based view (RBV) highlights the role of complementarities among strategic assets as a source of value creation. ${ }^{(30)}$ Complementarities are present whenever having a bundle of goods together provides more value than the total value of having each of the goods separately. ${ }^{(25,31)}$ One of the main aspects of complementarities in e-Business is to offer customers multiple channels in transactions. ${ }^{(32)} \mathrm{e}$-Business enables all participant firms to effectively use e-Business systems to support supply chain coordination and collaboration; thus, e-Business value can be created by combining various complementarities among activities, such as supply chain integration, and complementarities among technologies. ${ }^{(25)}$

Efficiency pertains to lowering the cost per transaction through e-Business. Owing to the speedy communications and convenience of the Internet, up-to-date information can be shared rapidly; thus, the improved information can reduce buyers' and sellers' searching and bargaining costs, enhancing the transaction efficiency. ${ }^{(25,33)}$ Thus, efficiency can be achieved 
if a firm's strategy and dynamic capabilities are aligned to leverage the Internet and its technologies to become cost-efficient. Therefore, we adopted these four variables (i.e., novelty, lock-in, complementarities, and efficiency), instead of the overall organizational performance, as the dependent variables.

\subsection{Alignment}

Alignment (fit) as covariation is a criterion-free perspective defined as "a pattern of covariation or internal consistency among a set of underlying theoretically related variables, and it can be best described through an illustration." (34) Its verbalization follows a strategy proposition that the degree of internal consistency among related variables or constituencies has a significant effect on performance. This concept of fit is similar to fit as gestalts, but the two concepts differ in the degree of specification of the functional form. Gestalts consider fit to be products of cluster analysis, in which observations can be grouped on the basis of a set of attributes, whereas covariation is the process of factor analysis, the grouping of attributes based on a set of observations. ${ }^{(34)}$ This is the reason why Lumpkin et al. stated: "This perspective requires much greater precision in the pattern of logical consistency among the factors and the explication of the underlying logical link among the attributes." (34) Although exploratory factor analysis (EFA) or confirmatory factor analysis (CFA) can be used to test this perspective of fit, the CFA approach is superior to the EFA approach for modeling fit as covariation.

\section{Hypothesis Development}

Academics and practitioners have developed some frameworks trying to explain and clarify the relationships between IT/IS and organizational strategy. However, in the e-Business field, although researchers recognize the importance of IT in the construction of e-Business activities, the fit relationship has not been validated by empirical study. This means that the fit issue in e-Business research is still in its infancy. Our research suggests that the successful development and implementation of competitive advantages for e-Business companies depend on a proper fit between e-Business strategy and e-Business IT capabilities. It has been shown that no single competitive strategy will lead to superior value; ${ }^{(35)}$ business value is created by the capabilities of an e-Business company to align its competitive position regarding its internal possessions ${ }^{(36)}$ and its strategic, tactical, and operative objectives. ${ }^{(37,38)}$

Some studies have discussed the relationships between IT, business departments, and the environment for e-Business companies. ${ }^{(39)}$ Meanwhile, evidence suggests that if the e-Business strategy fits well with organizational strategies, it will have a positive impact on organizational performance, ${ }^{(38,40,41)}$ especially in the context of value creation. ${ }^{(25,42)}$ For example, Porter ${ }^{(43)}$ indicated that the Internet is a means to alter competitive forces by either lowering costs or enhancing differentiation, which collectively determine industry profitability. The development of e-Business requires large-scale changes in both internal and external processes, and Pedraza et al. ${ }^{(38)}$ demonstrated that the fit of business strategy and e-Business processes supported by using IT is the key to creating value. By using empirical data collected from 107 
Canadian SMEs, Raymond and Bergeron ${ }^{(39)}$ attempted to acquire a deeper understanding of the fit between e-Business capabilities and strategic orientation. Results showed that the ideal e-Business profiles vary in relation to the firm's business strategy, whether it is of the defender, analyzer, or prospector type. Lu and Wang ${ }^{(42)}$ also mentioned that higher IT capability is a vital ingredient for e-Business success. Most important of all, e-Business IIoT strategy is the key factor in the executions of supply chain activities, especially in the support of IoT technologies. ${ }^{(9)}$ Hasselblatt et al. ${ }^{(41)}$ also proposed a conceptual framework indicating that a manufacturer's capabilities for the IoT can be obtained by digital business model development, building scalable solution platforms, IoT value selling, IoT value delivery, and business intelligence and measurement.

Although firms can take advantage of various tools and applications in deploying e-Business, the way to provide competitive advantages is to define a clear e-Business IIoT strategy with their use of Internet tools. ${ }^{(7)}$ Thus, in accordance with the fit perspective and RBV, we introduce two consistent and mutually dependent major constructs, namely, e-Business IIoT strategy and IIoT capabilities. The latent variable between e-Business IIoT strategy and IIoT capabilities is the alignment. The research model is shown in Fig. 1. As we can see in the research model, our research aims to investigate the alignment effect between e-Business IIoT strategy and IIoT capabilities on a firm's competitive advantages by measuring in the variables of novelty, lock-in, complementarities, and efficiency. The following hypothesis is also proposed:

Hypothesis 1: The higher the alignment between e-Business IIoT strategy and e-Business IIoT capabilities, the higher the level of e-Business value creation of a firm.

\section{Research Methodology}

\subsection{Measurement scale development}

Three latent constructs are proposed in this study, namely, e-Business IIoT strategy, e-Business IIoT capabilities, and e-Business value creation, with a total of 10 manifest

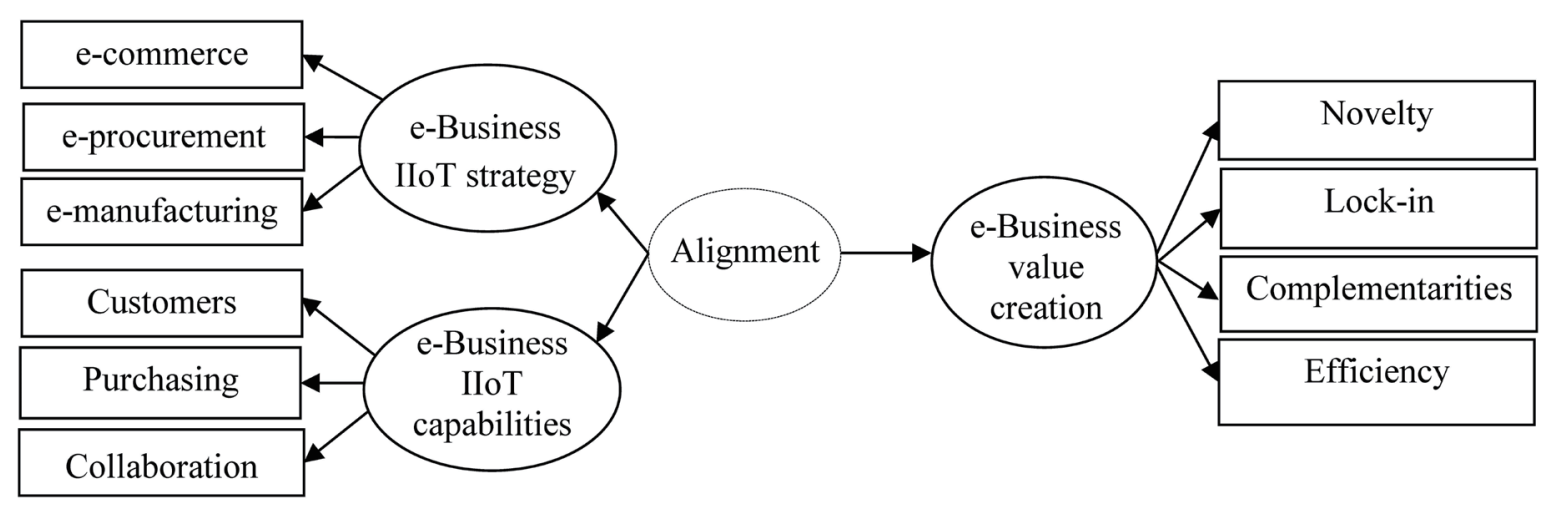

Fig. 1. Conceptual research model. 
variables. The fourth construct is the alignment, which is the latent variable for e-Business IIoT strategy and e-Business IIoT capabilities. A multiple-item method was used to construct the questionnaires. A seven-point Likert-type scale response format was provided. Wherever possible, for measurement validity, we adopted previous well-established research instruments, with only minor changes in wording. Most of the independent and dependent variables are operationalized on the basis of pertinent existing literature.

In total, 26 items were used to measure the 10 variables derived from three latent constructs. These items are given in Tables 1-3 along with their sources and scale ranges.

\subsection{Data collection and the respondents}

We used a survey-based and cross-sectional research strategy. To collect the empirical data, a mailing survey was carried out in a specific time frame. Mailing lists were excerpted from the China Credit Information Service (CCIS) database and included top-ranked manufacturing companies in Taiwan.

Table 1

e-Business IIoT strategy items. ${ }^{*}$ (7)

\begin{tabular}{ll}
\hline Variable & \multicolumn{1}{c}{ Item } \\
\hline $\begin{array}{l}\text { Please indicate to what extent does your company use IoT technologies (including RFIDs, sensors, 3D scanners, } \\
\text { cameras...etc.) and the web to integrate activities of the following processes. }\end{array}$ \\
\hline e-commerce & ec1: Sales \\
ec2: Customer service and support (CRM)
\end{tabular}

"Ranging from "None" to "High".

Table 2

e-Business IIoT capabilities measurement items ${ }^{*}$ (6)

\begin{tabular}{ll}
\hline Variable & \multicolumn{1}{c}{ Item } \\
\hline \multirow{2}{*}{ Customer } & $\begin{array}{l}\text { cu1: Allow customers to order products online by using IoT support instruments. } \\
\text { cu2: Allow customers to configure or customize products online by using IoT support instruments. } \\
\text { cu3: Allow customers to check the status of their orders online by using IoT support instruments. }\end{array}$ \\
\hline \multirow{2}{*}{ Purchasing } & $\begin{array}{l}\text { pu1: Find and select suppliers online for commodity components. } \\
\text { pu2: Purchase materials through online auctions. }\end{array}$ \\
\hline \multirow{2}{*}{ Collaboration } & $\begin{array}{l}\text { cl1: Support web-based EDI. } \\
\text { cl2: Enable collaboration with suppliers or customers on forecasting, scheduling, or replenishment } \\
\text { online by using IoT support instruments. } \\
\text { c3: Support advanced planning and scheduling (APS) to optimize supply chain performance. }\end{array}$ \\
\hline
\end{tabular}

"Ranging from "Not implemented" to "Fully implemented". 
Table 3

e-Business value creation measurement items. ${ }^{*}{ }^{(31)}$

\begin{tabular}{|c|c|}
\hline Variable & Item \\
\hline Efficiency & $\begin{array}{l}\text { ef1: Our e-Business efforts have reduced costs by electronic order taking over the Internet. } \\
\text { ef2: Our e-Business efforts have made us able to deliver faster. } \\
\text { ef3: Our e-Business efforts have reduced costs in communications with suppliers and } \\
\text { customers. }\end{array}$ \\
\hline Complementarities & $\begin{array}{l}\text { co1: As a result of our e-Business efforts, our products or services complement products or } \\
\text { services from other suppliers. } \\
\text { co2: Our e-Business efforts make it possible for other suppliers to complement our products } \\
\text { or services. } \\
\text { co3: Our e-Business efforts have made our supply chain strongly integrated to our partners' } \\
\text { supply chains. }\end{array}$ \\
\hline Lock-in & $\begin{array}{l}\text { 1k1: Our e-Business efforts make it more expensive for our customers or suppliers to replace } \\
\text { us. } \\
\text { 1k2: Our e-Business efforts have made our products and services more tailored to our } \\
\text { customers' needs. }\end{array}$ \\
\hline Novelty & $\begin{array}{l}\text { no1: Our e-Business efforts have made our company a pioneer in utilizing e-commerce } \\
\text { solutions. } \\
\text { no2: Our e-Business efforts have made us cooperate with our customers or suppliers in new } \\
\text { and innovative ways. }\end{array}$ \\
\hline
\end{tabular}

*Ranging from "Totally disagree" to "Totally agree".

In the survey research approach, distributing the questionnaire to the right person is critical. The unit of analysis of our research was an organization or strategic business unit (SBU). The respondents needed to be knowledgeable about their e-Business operations and activities, and IT deployment. Thus, executives (CIOs, CEOs, CKOs, and directors) and those responsible for devising e-Business and IT works were targeted to answer our questionnaire. A total of 194 surveys were returned, seven of which were incomplete, yielding 187 valid samples. The gross response rate was about $15.3 \%$.

\subsection{Data analysis technique}

SPSS version 18 and the structural equation modeling of confirmation factor analysis (CFA) were used to verify the reliability and validity of each construct. Model estimation was performed using the maximum likelihood fit function and a sample correlation matrix. CFA involves analysis of the measurement model, which demonstrated that the measurement model had sufficient validity and reliability for further model examination. ${ }^{(44)}$

According to Bergeron et al., ${ }^{(36)}$ the covariation approach of alignment is applicable to theory testing; thus, this methodology was employed for testing the alignment in this present study. Consequently, this "system approach" (i.e., the covariation perspective) involved considering all the e-Business strategy-IT capabilities simultaneously. The statistical analysis method for the covariation perspective is second-order CFA. Its underlying meaning is that fit is specified as a second-order construct derived from its first-order antecedents. Thus, SEM with partial least squares (PLS) was used to test the model. 


\section{Data Analysis and Results}

\subsection{Sample characteristics}

The characteristics of the samples are described as follows. The respondents were all from the manufacturing industry. Most of the companies had 100 to 499 employees (37.9\%). The respondents held various job titles, including senior manager, middle manager, and first-line manager. Approximately $60.2 \%$ of the respondents had more than six years of experience and almost half (47\%) had an undergraduate degree. Furthermore, the age of the participants ranged from " 21 " to "51 and above", with the largest percentage (39.8\%) in the 31 to 41 category. About $75 \%$ of the respondents were male.

\subsection{Hypothesis testing}

According to the arguments proposed by Venkatraman, ${ }^{(35)}$ alignment is specified as a second-order construct derived from two first-order constructs, which are e-Business strategy and IT capabilities. e-Business value creation is also considered a second-order construct composed of novelty, lock-in, complementarities, and efficiency. According to Venkatraman, ${ }^{(35)}$ even though the covariation approach can be modeled as exploratory factor analysis (EFA) and CFA, CFA is preferred as a tool to model fit as covariation.

Overall, the fit statistics demonstrated a good fit of the model with the following data collected from the validated measures: $\chi_{15}^{2}=23.96 ; \chi^{2} /$ d.f. $=2.37, p<0.001$; AGFI (adjusted goodness-of-fit index $)=0.92$; CFI (comparative fit index $)=0.99$; NFI (normed fit index $)=0.97$; NNFI (non-normed fit index) $=0.95$; SRMSR (standardized root mean square residual) $=0.042$. Therefore, according to Fig. 2, hypothesis 1 is supported. The fit effect on business performance was examined. All the paths exhibited significance at the $p<0.05$ level. The results showed that the fit explained $31 \%$ of the variance and had significant direct effects on e-Business value creation. Furthermore, the loadings from each latent variable to its manifest variables are also significant.

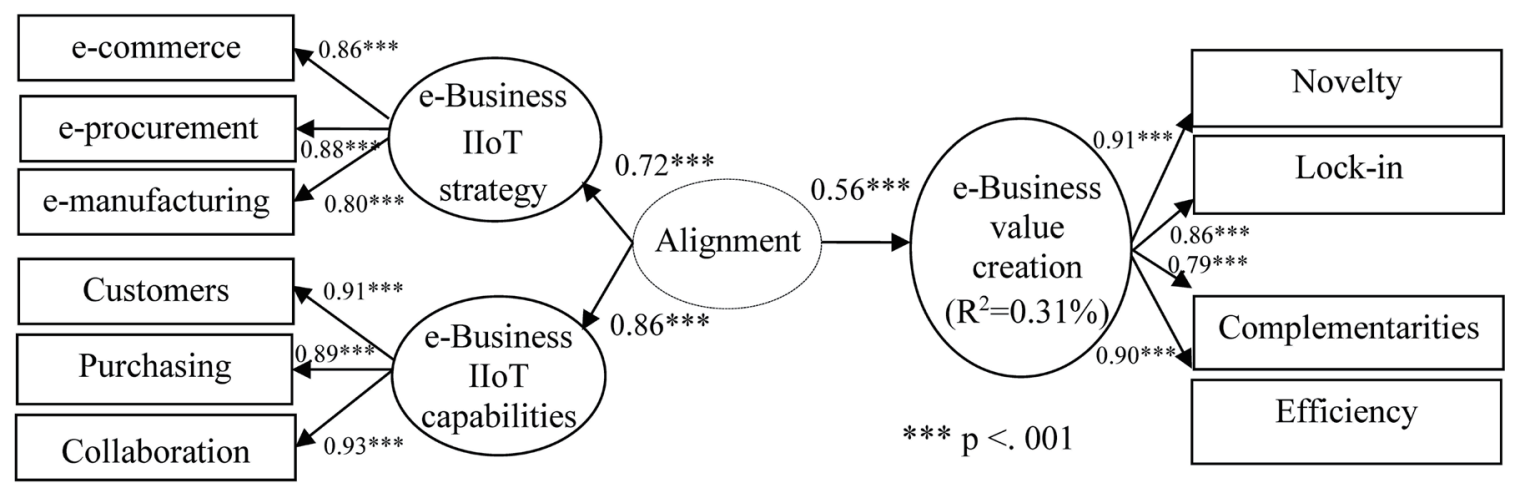

Fig. 2. Result of research model. 


\section{Conclusion and Discussion}

In the present study, the concept of e-Business IIoT strategy, IIoT capabilities, and value creation have been defined and discussed. The e-Business alignment relationships between strategy and IIoT capabilities have been corroborated. Finally, the alignment effects have also been examined by using the perspective of fit as covariation. The results support the hypothesis that the alignment between e-Business IIoT strategy and IIoT capabilities has a positive direct effect on e-Business value creation.

The development of e-Business IIoT capabilities in companies may come in different forms. For example, extending the traditional perspective of organizational capabilities to e-Business, Soto-Acosta and Merono-Cerdan ${ }^{(45)}$ categorized a firm's e-Business capabilities into two parts, namely, external (the ability to mobilize Internet-based resources and other corporate resources with external business agents) and internal (the ability to mobilize Internet-based resources and other corporate resources within a firm's boundaries). By employing these two capabilities correctly, the value creation of a firm can be enhanced. Considering the broad set of technologies used by firms to manage their supply chains, Poirier and Quinn ${ }^{(46)}$ also proposed eight technologies that most firms can use to achieve supply chain competency, including inventory planning and optimization, web-based applications, advanced planning and scheduling, and e-procurement systems. These technologies can be classified into three categories on the demand side, supply side, and collaboration side to realize an e-Business's competitive advantages. ${ }^{(6)}$ The demand side is concerned with how consumers order, configure, or customize products and check the status of orders online. The supply side focuses on the capability of the company to find and select suppliers online and purchase materials through online auctions. Finally, collaboration with customers or suppliers relates to web-based EDI, forecasting, inventory replenishment, and scheduling capabilities by applying IoT-related technologies. ${ }^{(41)}$ That is, owing to the complexity of technological choices, implementation difficulties, higher personnel training costs, and the need for continuous updating of IIoT technologies, it is necessary for firms to target their e-business activities on the basis of their IIoT strategy, as well as their IIoT capabilities.

Although firms can take advantage of various tools and applications in deploying e-Business, a better way to provide competitive advantages is to define a clear e-business IIoT strategy with their use of Internet tools. The present study introduced two consistent and mutually dependent major constructs, namely, e-Business IIoT strategy and e-Business IIoT capabilities. It is hypothesized that the fit between these two antecedents will contribute to value creation of a firm. Understanding the underlying meanings of a successful alignment between various strategies for firms is of interest to both practitioners and academics. The overall picture emerging from this study highlights the performance implications of alignment between two operational functions, namely, e-Business IIoT strategy and e-Business IIoT capabilities, which are critical for contemporary firms. To our knowledge, this is one of the few studies describing the performance implications of alignment between those dimensions. We hope this study can be regarded as the basis for future research in the alignment area with respect to e-Business IIoT strategy and IIoT strategy on business value creation. 


\section{Acknowledgments}

This study was supported by the research fund MOST 106-2410-H-214-014 granted by the Ministry of Science and Technology, R.O.C. and I-Shou University under project number ISU105-01-09.

\section{References}

1 P. Gottschalk: E-business Strategy, Sourcing, and Governance (Idea Group Publishing, Hershey PA, 2006).

2 D. Li, P. Y. K. Chau, and F. Lai: Decis. Sci. 41 (2010) 115. https://doi.org/10.1111/j.1540-5915.2009.00261.x

3 R. Kalakota and M. Robinson: e-Business 2.0: Roadmap for Success (Addison-Wesley, Massachusetts, 2001).

4 M. Essig and U. Arnold: J. Supply Chain Manage. 37 (2001) 43. https://doi.org/10.1111/j.1745-493X.2001. tb00112.x

5 A. Daghfous and N. Al-Nahas: SAM Adv. Manage. J. 71 (2006) 11.

6 S. Devaraj, L. Krajewski, and J. C. Wei: J. Oper. Manage. 25 (2007) 1199. https://doi.org/10.1016/j.jom.2007.01.002

7 R. Cagliano, F. Caniato, and G. Spina: Int. J. Oper. Prod. Manage. 23 (2003) 1142. https://doi.org/10.1007/9783-319-31104-3 6

8 B. Zhang, N. Mor, J. Kolb, D. S Chan, K. Lutz, E. Allman, J. Wawrzynek, E. A Lee, and J. Kubiatowicz: The Cloud is Not Enough: Saving IoT from the Cloud (2015).

9 J. Gubbi, R. Buyya, S., Marusic, and M. Palaniswami: Future Generation Comput. Syst. 29 (2013) 1645.

10 T. Eschberger: https:/www.lead-innovation.com/english-blog/industrial-internet-of-things (accessed January 2021).

11 J. Nagy, J. Olah, D. Mate, and J. Popp: Sustainability 10 (2018) 3491. https://doi.org/10.3390/su10103491

12 M. E. Porter: The Competitive Advantage of Nations (Free Press, New York, 1990).

13 H. Sun and C. Hong: Technovation 22 (2002) 699. https://doi.org/10.1016/S0166-4972(01)00066-9

14 A. M Croteau and F. Bergeron: J. Strategic Inf. Syst. 10 (2001) 77. https://doi.org/10.1016/S09638687(01)00044-0

15 E. Segev: Strategic Manage. J. 8 (1987) 565. https://doi.org/10.1002/smj.4250080606

16 J. Conway: https://download.schneider-electric.com/files?p_Doc_Ref=998-2095-10-16-15BR0_EN (accessed January 2021).

17 D. M. Lambert, C. C. Martha, and D. P. Janus: Int. J. Logist. Manage. 9 (1998) 1. https://doi. org/10.1108/09574099810805807

18 Accenture: https://www.accenture.com/acnmedia/Thought-Leadership-Assets/PDF/Accenture-IXOHannoverMesse-report.pdf/ (accessed December 2020).

19 E. Brynjolfsson and M. D. Smith: Manage. Sci. 46 (2000) 563. https://doi.org/10.1287/mnsc.46.4.563.12061

20 L. De Boer, J. Harink, and G. Heijboer: Eur. J. Purch. Supply Manage. 8 (2002) 25. https://doi.org/10.1016/ S0969-7012(01)00015-6

21 D. F. Kehoe and N. J. Boughton: Int. J. Oper. Prod. Manage. 21 (2001) 582. https://doi. org $/ 10.1108 / 01443570110390345$

22 F. Bergeron, L. Raymond, and S. Rivard: Inf. Manage. 41 (2004) 1003. https://doi.org/10.1016/j.im.2003.10.004

23 K. Zhu and K. L. Kraemer: Inf. Syst. Res. 13 (2002) 275. https://doi.org/10.1287/isre.13.3.275.82

24 A. S. Bharadwaj: MIS Q. 24 (2000) 169. https://doi.org/10.2307/3250983

25 J. I. Martinez and J. C. Jarillo: J. Int. Bus. Study 20 (1989) 489. https://doi.org/10.1057/palgrave.jibs. 8490370

26 R. Amit and C. Zott: Strategic Manage. J. 22 (2001) 493. https://doi.org/10.1002/smj.187

27 R. L. Plouffe: Inf. Executive 3 (1990) 25.

28 A. Basu and S. Muylle: MIT Sloan Manage. Rev. 49 (2007) 28.

29 D. F. Feeny and L. P. Willcocks: Long Range Plann. 31 (1989) 354. https://doi.org/10.1016/S00246301(98)00028-4

30 C. Zott and R. Amit: Long Range Plann. 43 (2010) 216. https://doi.org/10.1016/j.lrp.2009.07.004

31 J. B. Barney: J. Manage. 7 (1991) 99. https://doi.org/10.1177/014920639101700108

32 T. R. Eikebrokk and D. H. Olsen: Inf. Manage. 44 (2007) 364. https://doi.org/10.1016/j.im.2007.02.004

33 L. Kim and Y. Lim: Acad. Manage. J. 31 (1988) 802. https://doi.org/10.5465/256339

34 G. T. Lumpkin, S. B. Droege, and G. G. Dess: Organ. Dyn. 30 (2002) 325. https://doi.org/10.1016/S00902616(02)00065-7 
35 N. Venkatraman: Acad. Manage. Rev. 14 (1989) 423. https://doi.org/10.5465/amr.1989.4279078

36 F. Bergeron, L. Raymond, and S. Rivard: Omega 29 (2001) 125. https://doi.org/10.1016/S0305-0483(00)000347

37 M. Rashidirad, E. Soltani, and J. Syed: Strategic Change 22 (2013) 213. https://doi.org/10.1002/jsc.1934

38 N. Pedraza, M. Guerrero, and J. Lavin: J. Technol. Manage. Innovation 6 (2011) 206. https://doi.org/10.4067/ S0718-27242011000400015

39 L. Raymond and F. Bergeron: Ind. Manage. Data Syst. 108 (2008) 577. https://doi. org/10.1108/02635570810876723

40 D. J. Teece, G. Pisano, and A. Shuen: Strategic Manage. J. 18 (1997) 509. https://doi.org/10.1002/(SICI)10970266(199708)18:7<509::AID-SMJ882>3.0.CO;2-Z

41 M. Hasselblatt, T. Huikkola, M. Kohtamaki, and D. Nickell: J. Bus. Ind. Mark. 33 (2018) 822. https://doi. org/10.1108/JBIM-11-2015-0225

42 Y. G. Lu and E. T. Wang: J. e-Bus. 13 (2011) 491 (in Chinese). https://doi.org/10.6188/JEB.2011.13.01

43 M. E. Porter: Harv. Bus. Rev. 79 (2001) 62.

44 C. Fornell and D. E. Larcker: J. Mark. Res. 18 (1981) 39. https://doi.org/10.2307/3151312

45 P. Soto-Acosta and A. L. Merono-Cerdan: Int. J. Inf. Manage. 28 (2008) 49. https://doi.org/10.1016/ j.ijinfomgt.2007.05.001

46 C. C. Poirier and F. J. Quinn: Supply Chain Manage. Rev. 7 (2003) 40. 